\title{
Unmet Need for Contraception and its Associated Factors among Married Women of Reproductive Age in Simichaur VDC of Gulmi District
}

\author{
Kandel NR ${ }^{1}$ \\ ${ }^{1}$ District Health Office, Gulmi, Nepal
}

\begin{abstract}
Background

Nepal Demographic Heath Survey conducted in 2006, has indicated 26.4 percent of unmet need among married women of reproductive age had unmet need at national level. Unmet need for limiting was highest $(15.2 \%)$ where as spacing method constitutes at 9.4 percent. At western region, the vary region where the Gulmi district is situated unmet need is $32.4 \%$ with $36.6 \%$ of married women of reproductive age currently using contraceptives is lower than at the national level $(44.2 \%)$. The objective of the study was to find out the various factors associated with the unmet need for contraception among married women of reproductive age group in Simichaur VDC of Gulmi district

Methods

It was a descriptive, cross sectional, community based study. Altogether 131 married women of reproductive age were interviewed while the systematic random sampling method was designed for sampling procedure. Interview was done using semi-structured questionnaire for data collection.
\end{abstract}

\section{Results}

Among 131 Married women of reproductive age, 42 percent were found currently using modern contraceptive method. Forty eight percent of the married women of reproductive age had unmet need for contraception, 29.7 percent for limiting and 18.3 percent for spacing. Less than a half of the respondent ( 45.8 percent) were able to name all seven modern contraceptive methods with the correct information about their source

\section{Conclusion}

The unmet need for family planning was high and the major reason for non-use of contraception were absence of husband, fear of side effect and having no information about contraceptives. So, Program that focuses on correct information sharing about contraceptives with couple should be designed, communication and discussion about family planning between spouses, programs that encourage the involvement of men in family planning should be developed and implemented.

Key words: Contraceptives, Unmet need, men in family planing

\section{Introduction}

Concept of unmet need for contraception was developed from the early knowledge, attitude and practice (KAP) studies conducted during the 1960s and 1970s. Since then, numerous studies on KAP have shown that there exists a gap between women's desire for limiting or spacing children and use of contraception. The term KAP gap has been gradually replaced by the "unmet need". (1)

Currently married fecund women who want to postpone their next birth for two or more years or who want to stop childbearing altogether but are not using a contraceptive method are considered to have an unmet need for family planning. (2)

Since 1984, when the Demographic and Health Survey (DHS) program started, the concept of unmet need has become the topic of interest for family planning program. Over the past two decades, the goal of family planning policy of many countries have shifted from an emphasis on increasing contraceptive prevalence to satisfying unmet need which is clearly articulated in the program of action of the International Conference on Population and Development (ICPD) 1994. (3)

Nepal's family planning program is directed toward reaching couples with "unmet" need and reducing the proportion of women who expressed "no demand" through information and awareness activities. Both the current contraceptive prevalence rate (CPR) for modern method only- obtained from HMIS (Health Management Information System) data and finding of Nepal Demographic and Health Survey (NDHS) 2006 indicate that the met need for FP services has increased narrowing the gap of unmet need. But to strive for the Millennium Development Goal (MDG) of achieving 67 percent CPR from the current level by 2015 is a challenge that should be addressed by the program with innovative approaches and appropriate strategies. (4)

In view of the above, the present study was carried out with the objectives to find out the magnitude of unmet need for family planning among married women of reproductive age to identify factors associated with unmet need for family planning and contraceptive users. It is necessary to study the magnitude and factors contributing towards unmet need in different regions of Nepal due to cultural and geographical heterogeneity. Thus, the present study was planned to explore the factors related to unmet need for family planning in the Simichaur Village Development Committee (VDC) of Nepal.

CORRESPONDENCE : Nava Raj Kandel, District Health Office, Tamghas, Gulmi, Nepal. Email: navarajkandel@hotmail.com 


\section{Methods}

It was a descriptive, cross sectional, community based study. Altogether 131 married women of reproductive age were interviewed while the systematic random sampling method was designed for sampling procedure. Interview was done using semi-structured questionnaire for data collection. Data entry and analysis was done by using statistical software SPSS 17.0. Coding and recoding of variables was done to facilitate data entry and analysis. Relationship of unmet need for family planning among married women of reproductive age with different independent variables and background variables were compared and tested by using chi-square test (non-parameter test) with five percent level of significance.

Cross checking and editing of filled up data in the field was done to maintain internal consistency. If any error or missing was found during cross-checking, data was corrected \& verified by revisiting the same household Verbal consent was taken from and objectives of the study were explained to respondents prior to interview. Autonomy of the respondents was respected either to continue the interview or quit at any time. Confidentiality of the respondents was maintained.

\section{Results}

Total 131 married women of reproductive age were interviewed for the collection of data during study. The median age of respondents was 27 years. More than four-fifth (83.2 percent) of respondents were found at the age below 20 years. The median age of respondents at marriage was observed 18 years. More than half of the respondents (55.7 percent) were found having one child or two children. Majority of the respondents were involved in domestic work and agriculture (90.8 percent). Regarding the occupation of husband of the respondents, the finding indicates that more than half of the respondent's husband (52.7 percent) was outside the home for foreign employment. Almost all respondents were found literate (96.9 percent). More than three-fourth of the respondents (76.3 percent) were from medium economic status followed by poor economic status (21.4 percent).

Less than a half of the respondent (45.8 percent) were able to name all seven modern contraceptive methods with the correct information about their source. Respondents who have never heard about the contraceptives and could not state the name of any modern contraceptive method were 9.9 percent. More than two-third of respondents (66.9 percent) had accessibility of Depo-Provera, Pills and Condom within half an hour of easy walking distance.

More than two third of the respondents $(71.8 \%)$ had discussed and communicated with their husband about contraceptive use. Nearly two-third (63.4 percent) of respondents were found to have visited health workers for family planning services. Out of 83 respondents who visited to health worker, 86.7 percent expressed that they were provided FP counseling services by health worker. 13.7 percent of the respondents had their husband disagreed to use contraception. Similarly, only 4.6 percent of respondents expressed that their family members other than husband such as mother in law, father in law, brother in law etc. disagreed to use contraception.

Among 131 Married women of reproductive age, 55 respondents (42 percent) were found currently using modern contraceptive method during study period. Out of 55 respondents who were currently using contraception, 22.1 percent were using for spacing and 19.9 percent were for limiting. The distribution of current user according to method using shows that greater number of the respondents used female sterilization ( 25.5 percent) followed by male sterilization (21.8 percent). Percentage of Implant and IUD were found low.

Nearly half (48 percent) of respondents were not using any modern method of contraception though they did not want child bearing. Fecund non pregnant women of reproductive age who want to postpone child birth for at least two years but currently not using any contraceptive method were found 18.3 percent while fecund non pregnant women who want no more children but currently not using any contraceptive method were found 29.7 percent (table 1).

Table 1: Distribution of respondents by the type of unmet need for contraception

\begin{tabular}{l|c|c}
\hline Unmet need for contraception & $\begin{array}{c}\text { Frequency } \\
(\mathrm{n}=131)\end{array}$ & Percent \\
\hline Spacing method & 24 & 18.3 \\
\hline Limiting method & 39 & 29.7 \\
\hline Total unmet need & 63 & 48.0 \\
\hline
\end{tabular}

Similarly one of respondent was found pregnant, 8 respondents $(6.1 \%)$ mentioned that they were infecund and 4 respondents $(3 \%)$ wish to be pregnant later.

Those respondents who were found with unmet need for contraception were asked about the reason for not using contraception. Multiple or single answers for the reason were found. The table below reveals that the top most reason for nonuse of contraceptives responded was "husband out of home" (79.3 percent). Second most common response was "fear of side effect" (6.8 percent) (table 2$)$.

Table 2: Distribution of respondents with reasons for unmet need for contraception

\begin{tabular}{l|c|c}
\hline \multicolumn{1}{c|}{ Reason for unmet need } & $\begin{array}{c}\text { Frequency } \\
(\mathrm{n}=63)\end{array}$ & Percent \\
\hline Husband out of home & 50 & 79.3 \\
\hline Spacing method & 24 & 18.3 \\
\hline Fear of side effect & 9 & 14.3 \\
\hline No information & 4 & 6.3 \\
\hline Child's age less than 6 months & 4 & 6.3 \\
\hline Rumor about family planning & 2 & 3.2 \\
\hline Disapproval from religion & 1 & 1.6 \\
\hline No counseling service & 1 & 1.6 \\
\hline Disapproval of husband & 1 & 1.6 \\
\hline Disapproval of other family members & 1 & 1.6 \\
\hline
\end{tabular}


A significant association was observed of unmet need for contraception with various factors like number of living son, husband's occupation, feeling of fear of side effect of contraception, spousal discussion and communication about contraception and couple's visit to health worker for family planning services. Insignificant association was found between unmet need for contraception and women's age, ethnicity, occupation of respondents, education level of respondents and their husband, socio-economic status, women's knowledge on contraception, accessibility of contraceptives, family planning counseling and disapproval by husband as well as other family member.

\section{Discussion}

The main aim of the study was to investigate women's desire to limit or postpone childbearing and their practices of contraception use. The result shows that objectives of the study are achieved and is found similar with other studies conducted in the past.

In this study, it is found that 42 percent of married women of reproductive age were using a method of modern contraception with 22.1 percent spacing method and 19.9 percent limiting method. In other hand, 48 percent married women of reproductive age had unmet need for contraception with 18.3 percent for spacing method and 29.7 percent for limiting method. In other word, if all women with total unmet need were to use contraception the contraceptive prevalence rate would increase from 42 percent to 90 percent. Thus in brief, the level of unmet need and total demand for contraception in the study are higher than national and regional (Western Development Region) average but met need for contraception is nearly similar to national level and higher than regional level. (2) In one hand met need higher than regional level but nearly similar to national level indicates the effectiveness of family planning program and in other hand, high unmet need seems challenge to improve the program.

According to NDHS 2006, 26.4 percent of married women of reproductive age had unmet need for family planning at national level. Out of 26.4 percent, unmet need for spacing method was 9.4 percent while unmet need for limiting method constitutes 15.2 percent. At western regional level, unmet need is 32.4 percent with 10.4 percent spacing method and 22 percent limiting method. In other hand, 44.2 percent of married women of reproductive age were currently using a contraceptive method at national level while 36.6 percent of married women of reproductive age were currently using a contraceptive method at western regional level. (2) The contraceptive prevalence rate (42 percent) found from this study is higher than the reported prevalence rate of Gulmi district (30.1 percent) in FY 2009/2010. (4)

The study observed that there is inverse relationship between unmet need and age of the respondents. The percentage of met need was increasing with the increase in age of the respondent whereas the percentage of unmet need was decreasing with the increase in age of the respondent. It indicates that unmet need for contraception varies with age of women. Similar findings were found in NDHS 2006 (2) and the study conducted in rural area of Haryana, India. (5)

In this study, 19.8 percent women were found having no son and 32.9 percent women having 2 plus son. Women with no son were found to have high unmet need (69.6 percent) and those who have 2 plus sons having low unmet need (34.2 percent). Conversely, women with no son were found having low (30.4 percent) met need and women with 2 plus sons were found to have high met need. It reveals that unmet need for contraception varies with number of son. In this study, number of living son is found significantly associated with unmet need for contraception. It indicates that the son preference behavior of couple play a significant role to determine the unmet need for contraception. A study published in Kathmandu University Medical Journal (KUMJ) 2006 shows the reason behind unmet need was son preferences in the family. (6)

In this study, occupation is found not to be significantly associated with unmet need for contraception. However, occupation of husband of the respondents was found significantly associated with unmet need for contraception. Unmet need was higher (67.6 percent) among respondents whose husbands were foreign employee or student and lower (33.3 percent) in those whose husbands were involved in agriculture or business. It may be due to husband being out of home having important role in determination of both met and unmet need for contraception. A study named FP, Maternal, Newborn and Child Health Situation in Nepal 2010 conducted in 2009 revealed that unmet need is much higher among couples who are not living together than among living together. (4)

In this study, socio-economic status is found not to be significantly associated with unmet need for contraception. However, inverse relationship between socio-economic status and unmet need for contraception was seen. Unmet need was higher (54.2 percent) in respondents from poor socioeconomic class and lower (33.3 percent) in respondents from rich socio-economic class. According to NDHS 2006, unmet need is higher in lower wealth quintile (economic status) and vice versa. (2)

This study observed that there was no significant association between women's knowledge level and unmet need for contraception. However, there was inverse relationship seen in these variables. Unmet need was found higher (64.7 percent) in women having no knowledge and poor knowledge whereas it was lower (44.6 percent) in women having very good knowledge about contraception regarding method and source.

In this study, there was no significant association found between accessibility of Depo-Provera, Pills and Condom within half an hour of walking distance and unmet need for contraception. Unmet need among women having walking distance less than half an hour for contraception was similar 
to among women having walking distance more than half an hour.

This study observed that 55.9 percent respondents were found with feeling of fear of side effect. Those having feeling of fear, 59.1 percent were perceived by friends/relatives. Furthermore, 6.8 percent respondents mentioned that the fear of side effect is the main reason for non use of contraception. Feeling of fear is found significantly associated with unmet need for contraception ( $\mathrm{p}=0.010)$. Unmet need was high $(61.7$ percent) in women having feeling fear of side effect and low (36.7 percent) in women having no fear of side effect. Furthermore, Perception of feeling of fear of side effect due to others' experience was also found to be significantly associated with unmet need for contraception $(\mathrm{p}=0.001)$. Unmet need was found high (79.4 percent) and met need low (20.6 percent) among respondents who perceived feeling of fear of side effect as compared to those who experienced themselves were low unmet need (38.5 percent) and high met need (61.5 percent). It is concluded that fear of side effect is most important factor affecting unmet need for contraception. NDHS 2006 shows that 10 percent women mentioned fear of side effect as reason for non use of contraception. (2)

In this study, 71.8 percent women were found having interspousal communication with their husband. There is significant relationship between discussion and communication about contraception among spouses and unmet need for contraception ( $\mathrm{p}=0.000$ ). Among respondents having no discussion and communication about contraception among spouses, there was found high unmet need (83.3 percent) and low met need (16.7 percent) as compared to those having discussion and communication about contraception between spouses low unmet need (43.2 percent) and high met need (56.8 percent). This study reveals that inter-spousal communication about use of contraception is an important factor affecting unmet need for contraception. NDHS 2006 shows that 56.6 percent women never discussed about family planning with their spouse while 12.2 percent discussed 3 or more times with their spouse in the past year. (2)

This study observed that relationship between couple's visit to health worker for FP services and unmet need for contraception is highly significant $(\mathrm{p}=0.000)$. Respondents who didn't visit health worker for FP services were found to have high unmet need ( 90.2 percent) and low met need ( 9.8 percent) as compared to those who visited health worker were found to have low unmet need (33.8 percent) and high met need (66.2 percent). This is concluded that couple's visit to health worker for FP services is an important factor determining unmet need for contraception.

In this study, FP counseling and unmet need for contraception were not found significantly associated. However, respondents who didn't get FP counseling were found to have low unmet need (44.4 percent) and high met need (55.6 percent) and those respondents who get FP counseling were also found to have low unmet need (32.4 percent) and high met need (66.2 2 percent).
This study observed that 13.7 percent women experienced husband disapproval while 4.6 percent experienced family member's disapproval to use contraception. However, disapproval of husband and family member to use contraception and unmet need for contraception were not found significantly associated in this study. NDHS 2006 reported that 3.2 percent women mentioned husband opposed while 0.3 percent women mentioned other family member opposed as the reason for non use of contraception. (2)

\section{Conclusion}

The overall objective of study was to assess the major factors associated with unmet need for contraception. The study has identified important information regarding magnitude and major factors associated with unmet need for contraception.

Level of unmet need and total demand for contraception in the study were higher than national and regional (western development region) figure but met need for contraception is nearly similar to national level and higher than regional level. In comparison with district contraceptive prevalence rate, the prevalence of contraception is also found high. A big gap between total demand and contraception use challenges to improve the program of the district. The program focusing on correct information sharing with couple to reduce the feeling of fear of side effect of contraception should be designed. Early marriage behavior and high unmet need should be addressed by conducting specific information, education and communication (IEC) intervention.

\section{References:}

1. Pradhan A, Ban B. Program options to meet unmet need: In Insights on Family Health Issues in Nepal. Calverton, Maryland, USA: Macro International Inc.;1997.

2. Ministry of Health and Population (MoHP) [Nepal], New ERA, and Macro International Inc. Nepal Demographic and Health Survey 2006. Kathmandu, Nepal: Ministry of Health and Population; New ERA; and Macro International Inc.;2007.

3. Subedi GR. Unmet Need for Contraception and it's Determinants among Married Women of Reproductive Age in Dang District [MPH Thesis]. Kathmandu, Nepal: Department of Community Medicine and Family Health, Maharajgunj Medical Campus, Tribhuvan University; 2006.

4. Department of Health Services (DoHS) [Nepal]. Annual Report: Department of Health Services 2066/67 (2009/2010). Kathmandu, Nepal: DoHS/MoHP;2011.

5. Choudhary S, Saluja N, Sharma S, Gaur DR, Pandey SM. A Study on the Extent and Reasons of Unmet Need for Family Planning among Women of Reproductive Age Group in Rural Area of Haryana. The Internet Journal of Health. 2011;12(1).

6. Bhandari GP, Premarajan KC, Jha N, Yadav BK, Paudel IS, Nagesh S. Prevalence and determinants of unmet need for family planning in a district of eastern region of Nepal. Kathmandu Univ Med J (KUMJ). 2006 Apr-Jun;4(2):203-10. 